\title{
Upregulation of ICAM-1 and IL-1ß protein expression promotes lung injury in chronic obstructive pulmonary disease
}

\author{
Y.X. Wang ${ }^{1}$, M.L. Ji ${ }^{2}$, C.Y. Jiang ${ }^{3}$ and Z.B. Qian ${ }^{4}$ \\ ${ }^{1}$ Department of Pathophysiology, Xinxiang Medical University, Xinxiang, \\ Henan, China \\ ${ }^{2}$ Department of Physiology, Xinxiang Medical University, Xinxiang, Henan, \\ China \\ ${ }^{3}$ Editorial Department of Journal of Zhengzhou University, Zhengzhou, \\ Henan, China \\ ${ }^{4}$ Department of Functional laboratory, Xinxiang Medical University, \\ Xinxiang, Henan, China \\ Corresponding author: Z.B. Qian \\ E-mail: zhibinqian@126.com
}

Genet. Mol. Res. 15 (3): gmr.15037971

Received October 30, 2016

Accepted June 7, 2016

Published August 18, 2016

DOI http://dx.doi.org/10.4238/gmr.15037971

Copyright $(92016$ The Authors. This is an open-access article distributed under the terms of the Creative Commons Attribution ShareAlike (CC BY-SA) 4.0 License.

\begin{abstract}
Chronic obstructive pulmonary disease (COPD) is a devastating lung disorder characterized by sustained airway flow restriction that is not fully reversible. The precise pathogenic mechanisms are unknown, but it is clear that cigarette smoking and chronic inflammatory stimulation are the major causes of COPD. Lung inflammation associated with COPD involves multiple cytokines, aggregation, and activation of neutrophils in the airway and lung tissue, and release of proteases and oxygen free radicals. In this study, a rat model of COPD was established by daily cigarette smoke exposure plus
\end{abstract}


endotoxin treatment (the experimental group). Respiratory curves were recorded by the BL-420 biological signal collecting and processing system. Furthermore, the contents of inflammatory mediators, intercellular adhesion molecular (ICAM)-1 and interleukin (IL)-1 $\beta$, in bronchoalveolar lavage fluid (BALF) were determined by enzyme linked immunosorbent assay for experimental, smoke-exposed only (control), and untreated (blank) rat groups. Protein expression levels of ICAM-1 and IL-1 $\beta$ in the lung tissue were also compared among groups by the immunohistochemical streptavidin-peroxidase method. The COPD model rats exhibited severe dyspnea and lung inflammation as evidenced by significantly prolonged expiratory duration, higher respiratory rate, elevated ICAM- 1 and IL- $1 \beta$ in BALF, and higher ICAM-1 and IL-1 $\beta$ protein expression in lung tissue compared to control and blank group rats. Chronic cigarette smoke exposure plus endotoxin is a feasible and reliable model of COPD that recapitulates many clinical signs and pathogenic responses. ICAM-1 and IL-1 $\beta$ upregulation are possible early contributors to COPD-associated inflammatory lung injury.

Key words: Chronic obstructive pulmonary disease; Interleukin-1b; Inflammatory response; Intercellular adhesion molecule-1

\section{INTRODUCTION}

Chronic obstructive pulmonary disease (COPD) is a potentially fatal respiratory system disease characterized by sustained obstruction of lung airway flow (Maltais et al., 2014). Epidemiological data show that smoking and recurrent respiratory tract infections are the major causes underlying the development and evolution of COPD (Sin and Man, 2003). The pathogenesis of COPD is complex and not fully understood, but chronic inflammatory injuries of the airway, pulmonary parenchyma, and pulmonary vessels are the main characteristic changes observed in COPD (Arnson et al., 2010), implicating dysregulation of proinflammatory mediators in both lung tissue and the pulmonary vasculature.

Intercellular adhesion molecule-1 (ICAM-1) is a single-strand glycoprotein of the immunoglobulin superfamily that mediates adhesion between leukocytes and stromal cells as well as between leukocytes and vascular endothelial cells. It also activates the adhesion and aggregation of leukocytes, leading to the expression and release of multiple proinflammatory cytokines (Gahmberg et al., 1997; Vogel et al., 2006). The expression level of ICAM-1 may reflect the degree of inflammatory injury. Under normal physiological conditions, there is little or no expression of ICAM-1, including in the lung (Adams and Nash, 1996; Roebuck and Finnegan, 1999; Rahman et al., 2000; Frey et al., 2002; Rahman and Fazal, 2009). However, when risk factors lead to increased expression in endothelial cells, ICAM-I may interact with integrins on the surface of neutrophils, causing activation and chemotaxis. These activated leukocytes adhere, aggregate, and release proinflammatory factors that disrupt control of the inflammatory response, leading to inflammatory injury (Eniola et al., 2005; Forlow and Ley, 2001; Muller, 2011; Sun et al., 2011).

Interleukin (IL)-1 $\beta$ is another critical early promoter of the inflammatory cascade

Genetics and Molecular Research 15 (3): gmr.15037971 
(Dinarello, 2011; Ridker et al., 2011) that activates vascular endothelial cells, increases vascular permeability, promotes transmembrane migration of neutrophils, enhances the release of other inflammatory mediators, induces or upregulates the expression of adhesion molecules in vascular endothelial cells, and promotes further neutrophil aggregation (Ichikawa et al., 2002; Kanneganti, 2010; Ben-Sasson et al., 2011).

In this study, a COPD model rat was established that exhibited severe ventilation dysfunction caused by airway stenosis and flow limitation, as well as higher ICAM-1 and IL$1 \beta$ expression and release in lung tissue compared to untreated and smoke-only groups.

\section{MATERIAL AND METHODS}

\section{Materials and reagents}

Rabbit anti-rat polyclonal antibodies against IL- $1 \beta$ and ICAM-1 were obtained from Beijing Biosynthesis Biotechnology Co., Ltd. (Beijing, China). Specific IL-1 $\beta$ and ICAM-1 enzyme-linked immunosorbent assay (ELISA) kits were obtained from Beijing Zhongshan Golden Bridge Biotechnology Co., Ltd. (Beijing, China) and results were determined using a DG5031 ELISA analyzer (Nanjing Huadong Electronics Group Medical Equipment Co., Ltd., Nanjing, China). Respiration was measured using a BL-420 biological signal collecting and processing system (Chengdu TME Technology Co, Ltd., Chengdu, China). Cigarette smoke was supplied by Sanhua filter-tipped cigarettes (China Tobacco Henan Industrial Co., Ltd., Zhengzhou, China) containing $13 \mathrm{mg}$ tar, $1.0 \mathrm{mg}$ smoking nicotine (nicotine), and $14 \mathrm{mg}$ carbon monoxide per cigarette.

\section{Animal groups}

Thirty healthy conventional Sprague-Dawley $(\mathrm{SD})$ rats $(150 \pm 10 \mathrm{~g})$ provided by the Laboratory Animal Center of Zhengzhou University (Zhengzhou University, Zhengzhou, China) were randomized into three groups: experimental, control, and blank groups.

\section{Animal experiment}

Experimental group rats were placed in a $60 \times 40 \times 30 \mathrm{~cm}$ smoke exposure box for 30 min, twice daily, for 28 consecutive days as described (Zheng, 2003; Zhang et al., 2010). Endotoxin (lipopolysaccharide) was administered at $1 \mathrm{mg} / \mathrm{kg}$ by intratracheal instillation on days 1 and 14 ( $1 \mathrm{~d}$ and $14 \mathrm{~d}$ ). Rats in the control group were given equal-volume normal saline by intratracheal instillation on $1 \mathrm{~d}$ and $14 \mathrm{~d}$. All other procedures were the same as the experimental group. Rats in the blank group were not treated with smoke exposure or intratracheal instillation, but all other procedures were identical. On day 29 (29d), all rats were anesthetized by intraperitoneal injection of $4 \%$ chloral hydrate at $10 \mathrm{~mL} / \mathrm{kg}$ and an incision was made below the xiphoid process. Two needle electrodes were installed on either side of the diaphragm and connected to a BL-420 system to record the respiratory curve, after which rats were sacrificed and the entire lung removed for bronchoalveolar lavage fluid (BALF) and immunohistochemistry. A 5-mL BALF sample was taken and ICAM-1 and IL-1 $\beta$ concentrations were determined by ELISA. The lung tissues were then fixed in $4 \%$ paraformaldehyde, paraffin-embedded, sliced, and stained with hematoxylin and eosin

Genetics and Molecular Research 15 (3): gmr.15037971 
(H\&E). The expression levels of ICAM-1 and IL-1 $\beta$ proteins in lung tissues and cells were estimated by immunohistochemistry.

\section{ELISA method}

The BALF sample $(5 \mathrm{~mL})$ was centrifuged at $1500 \mathrm{rpm}$ for $10 \mathrm{~min}$. The supernatant was added to the ELISA plate and incubated at room temperature for $120 \mathrm{~min}$. The plate was washed and the color solution added for $20 \mathrm{~min}$ at room temperature. The staining reaction was stopped and the solution mixed for $30 \mathrm{~s}$. Optical density (OD) was read at $450 \mathrm{~nm}$ on a microplate reader. Standard curves were plotted (OD values $v s$ concentration) using the Curxpt software to estimate BALF protein content.

\section{Immunohistochemistry}

Lung tissues were formalin-fixed, paraffin-embedded, deparaffinized, incubated with $3 \% \mathrm{H}_{2} \mathrm{O}_{2}$ to quench endogenous peroxidase activity, and blocked with normal goat serum. Rabbit anti-rat ICAM-1/IL-1 $\beta$ antibodies and horseradish peroxidase-conjugated goat antirabbit IgG were added drop by drop, incubated with the chromogen diaminobenzidine, and counterstained with H\&E.

\section{Statistical analysis}

All data were imported into the SPSS10.0 software (Chicago, IL, USA) for analysis. Continuous variables are reported as means \pm standard deviation and group means compared by the independent-sample $t$-tests. Categorical data were compared by $\mathrm{c}^{2}$ tests. The correlation between expression of ICAM-1 and expression of IL- $1 \beta$ in lung tissues was assessed by Spearman's rank correlation. Significance was set at $\mathrm{P}<0.05$.

\section{RESULTS}

\section{Rats exposed to daily cigarette smoke plus endotoxin instillation exhibited severe expiratory dyspnea}

The respiratory curves of experimental (cigarette smoke + endotoxin), control (cigarette smoke only), and blank (untreated) group rats were measured on $29 \mathrm{~d}$ by a BL-420 biological signal collecting and processing system to examine general respiratory function (Table 1). The mean inspiratory duration was significantly lower in the experimental group than in the blank group $(t=6.125, \mathrm{P}<0.001)$ and control group $(t=10.511, \mathrm{P}<0.001)$, and lower in the control group than in the blank group $(t=8.225, \mathrm{P}<0.001)$. Conversely, expiratory duration was significantly longer in the experimental group than in the control group $(t=17.327, \mathrm{P}<0.001)$ and the blank group $(t=13.261, \mathrm{P}<0.001)$, and longer in the control group than in the blank group $(t=10.025, \mathrm{P}<0.05)$. Respiratory amplitude was also significantly lower in the experimental group than in both the control group $(t=21.412, \mathrm{P}$ $<0.001)$ and the blank group $(t=13.225, \mathrm{P}<0.001)$, and lower in the control group than in the blank group $(t=10.122, \mathrm{P}<0.05)$. Respiratory rate was significantly higher in the experimental group than in the control group $(t=14.085, \mathrm{P}<0.001)$ and the blank group $(t$ 
$=14.172, \mathrm{P}<0.001)$, and higher in the control group than in the blank group $(t=15.027, \mathrm{P}$ $<0.001)$. Thus, daily exposure to cigarette smoke induced pervasive respiratory dysfunction, which was exacerbated by endotoxin installation.

Table 1. Mean respiratory parameters for each rat group ( $N=10$ /group, means $\pm S D)$.

\begin{tabular}{l|c|c|c|c}
\hline Group & Inspiratory duration $(\mathrm{ms})$ & Expiratory duration $(\mathrm{ms})$ & Amplitude $(\mathrm{g})$ & Frequency (times/min) \\
\hline Experimental & $364.37 \pm 54.24$ & $493.46 \pm 122.31$ & $4.09 \pm 1.27$ & $71 \pm 16$ \\
\hline Control & $371.42 \pm 53.16$ & $489.27 \pm 117.63$ & $4.17 \pm 1.32$ & $63 \pm 12$ \\
\hline Blank & $371.60 \pm 90.07$ & $456.75 \pm 113.48$ & $4.87 \pm 1.54$ & $59 \pm 11$
\end{tabular}

Cigarette smoke with and without endotoxin instillation significantly enhanced ICAM1 and IL- $1 \beta$ concentrations in BALF (Tables 2 and 3). The concentration of ICAM-1 in BALF was significantly higher in experimental group rats than in either control group $(t=10.025, \mathrm{P}$ $=0.001)$ or blank group rats $(t=13.122, \mathrm{P}=0.001)$ as measured by ELISA. Similarly, BALF IL-1 $\beta$ concentration was significantly higher in experimental group rats compared to both control group $(t=16.270, \mathrm{P}=0.001)$ and blank group rats $(t=11.045, \mathrm{P}=0.000)$. Cigarette smoke exposure alone also significantly increased BALF concentrations of ICAM-1 and IL$1 \beta$ compared to untreated rats.

Table 2. ICAM-I concentrations in BALF (means $\pm \mathrm{SD}, \mathrm{mg} / \mathrm{L}$ ).

\begin{tabular}{l|c|c|c|c}
\hline Group & $\mathrm{N}$ & ICAM-1 & $t$-value & P value \\
\hline Experimental & 10 & $45.27 \pm 6.22$ & $10.025^{*}$ & $0.001^{*}$ \\
\hline Control & 10 & $42.69 \pm 4.16$ & $13.122^{* *}$ & $0.001^{* *}$ \\
\hline Blank & 10 & $30.62 \pm 3.13$ & & \\
\hline
\end{tabular}

*Experimental group $v s$ control group. **Experimental group $v s$ blank group.

Table 3. IL-1 $\beta$ concentrations in BALF (means $\pm \mathrm{SD}$, ng/L).

\begin{tabular}{l|c|c|c|c}
\hline Group & $\mathrm{N}$ & $\mathrm{IL}-1 \beta$ & $t$-value & P value \\
\hline Experimental & 10 & $247.21 \pm 32.47$ & $16.270^{*}$ & $0.001^{*}$ \\
\hline Control & 10 & $188.26 \pm 42.36$ & $11.045^{* *}$ & $0.000^{* *}$ \\
\hline Blank & 10 & $106.52 \pm 39.24$ & & \\
\hline
\end{tabular}

*Experimental group $v s$ control group. ${ }^{* *}$ Experimental group $v s$ blank group.

\section{ICAM-1 and IL-1ß protein expression levels were upregulated in lung tissue and cells of experimental group rats}

Immunohistochemical staining of ICAM-1 resulted in brownish granules distributed over the plasma membrane and cytoplasm (Figure 1), while tumor necrosis factor (TNF)- $\alpha$ immunostaining resulted in brownish granules distributed only in cytoplasm. Expression levels were estimated by semi-quantitative densitometry and compared among groups by $\chi^{2}$ tests. Expression of ICAM-1 was significantly higher in the experimental group than in both the control group $\left(\chi^{2}=9.24, \mathrm{P}<0.05\right)$ and blank group $\left(\chi^{2}=7.21, \mathrm{P}<0.05\right)$, and higher in the control group than in the blank group $\left(\chi^{2}=8.46, \mathrm{P}<0.05\right)$ (Table 4). Similarly, TNF- $\alpha$ expression was significantly higher in the experimental group than in the control group $\left(\chi^{2}=\right.$ $6.52, \mathrm{P}<0.05)$ and the blank group $\left(\chi^{2}=5.93, \mathrm{P}<0.05\right)$, and higher in the control group than in the blank group $\left(\chi^{2}=7.54, \mathrm{P}<0.05\right)$ (Table 5). Expression levels of ICAM-1 and IL-1 $\beta$ in lung tissue and cells of experimental group rats were positively correlated $(r=0.392, P=$

Genetics and Molecular Research 15 (3): gmr.15037971 
0.017) (Table 6). Thus, chronic cigarette smoke exposure induced an inflammatory reaction in lung tissue that was further exacerbated by endotoxin installation.
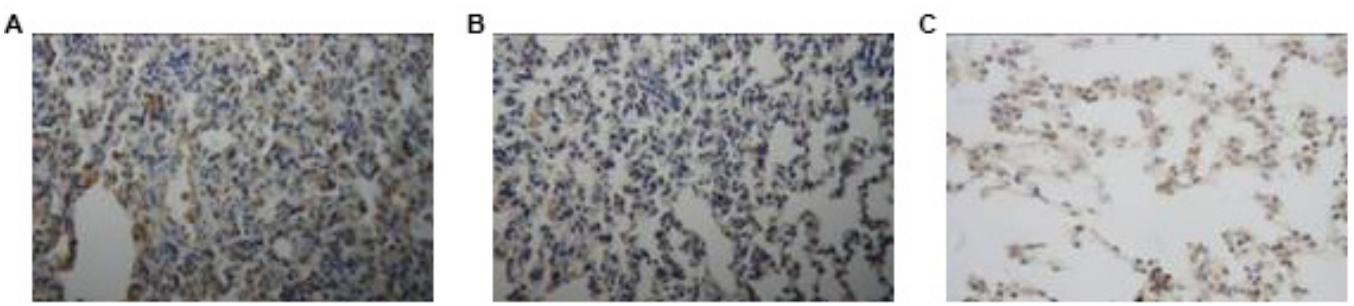

Figure 1. Immunohistochemical expression of ICAM-1 in lung tissue (400X). Exposure to cigarette smoke plus endotoxin (A. experimental group) enhanced lung ICAM-1 expression to a greater extent than cigarette smoke alone (B. control group), while little expression was observed in untreated rats (C. blank group).

Table 4. Expression of ICAM-1 in lung tissue and cells $(\mathrm{N}=10)$.

\begin{tabular}{l|c|c|c|c|c|c}
\hline \multirow{2}{*}{ Group } & \multicolumn{3}{|c|}{ ICAM-1 } & \multirow{2}{*}{$\chi^{2}$} & \multirow{2}{*}{ P value } \\
\cline { 2 - 7 } & - & + & ++ & +++ & & \\
\hline Experimental & 1 & 2 & 5 & 2 & & $7.21^{*}$ \\
\hline Control & 2 & 3 & 4 & 1 & $8.46^{* *}$ & $0.000^{*}$ \\
\hline Blank & 8 & 1 & 1 & 0 & $0.001^{* *}$ \\
\hline
\end{tabular}

*Experimental group $v s$ control group. **Experimental group $v s$ blank group.

Table 5. Expression of IL-1 $\beta$ in lung tissue and cells $(\mathrm{N}=10)$.

\begin{tabular}{l|c|c|c|c|c|c}
\hline Group & \multicolumn{7}{|c|}{ IL-1 $\beta$} & \multirow{2}{*}{$\chi^{2}$} & \multirow{2}{*}{ P value } \\
\hline & - & + & ++ & +++ & & \\
\hline Experimental & 0 & 1 & 5 & 4 & & \\
\hline Control & 0 & 4 & 3 & 3 & $5.93^{*}$ & $0.000^{*}$ \\
\hline Blank & 5 & 3 & 2 & 0 & $6.24^{* *}$ & $0.000^{* *}$ \\
\hline
\end{tabular}

*Experimental group $v s$ control group. **Experimental group $v s$ blank group.

Table 6. Correlation analysis on expression of ICAM-1 and expression of IL-1 $\beta$ in the lung tissues and cells of the rats in the experimental group $(\mathrm{N}=10)$.

\begin{tabular}{|c|c|c|c|c|c|}
\hline \multirow[t]{2}{*}{ ICAM-1 } & \multicolumn{4}{|c|}{ IL-1 $\beta$} & \multirow[t]{2}{*}{ Total } \\
\hline & - & + & ++ & +++ & \\
\hline- & 0 & 1 & 1 & 0 & 2 \\
\hline+ & 0 & 1 & 1 & 1 & 3 \\
\hline++ & 0 & 0 & 2 & 1 & 3 \\
\hline+++ & 0 & 0 & 1 & 1 & 2 \\
\hline Total & 0 & 2 & 5 & 3 & 10 \\
\hline
\end{tabular}

\section{DISCUSSION}

COPD is now the fourth leading cause of death worldwide and will ascend to third by 2030 (Menezes et al., 2005; Lopez et al., 2006a,b; Lozano et al., 2012). Smoking and respiratory tract infection are the two major contributors to COPD (Rabe et al., 2007), so we established a SD rat model of COPD by daily cigarette smoke exposure plus intratracheal instillation of endotoxin, which are bacterial wall lipopolysaccharides that induce an inflammatory 
response akin to that of Gram-negative bacterial infection. This model recapitulates the major pathogenic factors as well as the clinical features of human COPD, including upregulation of pro-inflammatory cytokines and concomitant dyspnea.

Respiratory curve monitoring showed respiratory dysfunction in rats exposed to daily cigarette smoke as indicated by significantly shorter inspiration, longer expiration, reduced respiratory amplitude, and higher respiratory rate, and even more severe dysfunction was observed in rats exposed to both cigarette smoke and endotoxin (Table 1). Thus, cigarette smoke exposure caused airway stenosis and flow limitation, which were exacerbated by intratracheal instillation of endotoxin. These symptoms conform to the main clinical manifestations of COPD, airflow obstruction and increased small airway resistance.

Patients with COPD show prominent airway hyper responsiveness that is widely believed to result from airway inflammation (Sin et al., 2002; Fabbri and Rabe, 2007). Similarly, this COPD model exhibited both enhanced release of the proinflammatory cytokines ICAM-1 and IL-1 $\beta$ into BALF and greater ICAM-1 and IL- $1 \beta$ expression in lung tissue than untreated rats (blank group) and rats exposed to cigarette smoke only (control group), while control rats exhibited significantly higher expression and release than untreated rats. Thus, rats exposed to cigarette smoke exhibited pathological manifestations of chronic inflammatory injury, and this response was even more severe in rats also subjected to endotoxin installation. Cigarette smoking as a physical and chemical factor and endotoxin as a biological factor may additively or synergistically upregulate the expression of ICAM-1 in epithelial cells of the pulmonary circulation and/or alveolar epithelial cells and increase the release of IL- $1 \beta$ by direct contact with the respiratory membrane, consistent with the enhanced dyspnea in the experimental group compared to the smoking only group.

Bird et al. (2010) reported decreased IL-1 $\beta$ in lung tissue and plasma of ICAM-1 knockout mice, consistent with the significant correlation between ICAM-1 and IL-1 $\beta$ expression in the lung tissue of experimental group rats observed in this study $(\mathrm{r}=0.392, \mathrm{P}=$ 0.017 ). We suggest that upregulated ICAM-1 expression activates neutrophils and promotes IL-1 $\beta$ release, initiating an inflammatory cascade. Furthermore, upregulation of ICAM-1 may be a critical early pathogenic response in COPD.

In conclusion, we established an animal model of COPD by concomitant exposure to two major risk factors, cigarette smoke and intratracheal endotoxin associated with bacterial infection. These animals exhibited signs of respiratory dysfunction due to airflow obstruction and increased small airway resistance, similar to COPD patients, underscoring the validity of this model for studies of COPD pathogenesis and treatment. Moreover, invasion of the airway with cigarette smoke and endotoxin upregulated ICAM1 expression in tracheal and alveolar epithelial cells, possibly activating the release of IL$1 \beta$. Together, ICAM-1 and IL-1 $\beta$ upregulation in lung tissue and pulmonary circulation may promote the release of other cytokines and inflammatory mediators, further expanding the inflammatory cascade and ultimately leading to respiratory dysfunction due to chronic airway stenosis and flow limitation.

\section{Conflicts of interest}

The authors declare no conflict of interest.

Genetics and Molecular Research 15 (3): gmr.15037971 


\section{ACKNOWLEDGMENTS}

Research supported by the Henan Province Technology Department Project (\#132300410160), the Henan Province Education Department Project (\#2011GGJS-127), and the Henan Province Education Department Project (\#2010B180024).

\section{REFERENCES}

Adams DH and Nash GB (1996). Disturbance of leucocyte circulation and adhesion to the endothelium as factors in circulatory pathology. Br. J. Anaesth. 77: 17-31. http://dx.doi.org/10.1093/bja/77.1.17

Arnson Y, Shoenfeld Y and Amital H (2010). Effects of tobacco smoke on immunity, inflammation and autoimmunity. $J$. Autoimmun. 34: J258-J265. http://dx.doi.org/10.1016/j.jaut.2009.12.003

Ben-Sasson SZ, Caucheteux S, Crank M, Hu-Li J, et al. (2011). IL-1 acts on T cells to enhance the magnitude of in vivo immune responses. Cytokine 56: 122-125. http://dx.doi.org/10.1016/j.cyto.2011.07.006

Bird MD, Morgan MO, Ramirez L, Yong S, et al. (2010). Decreased pulmonary inflammation after ethanol exposure and burn injury in intercellular adhesion molecule-1 knockout mice. J. Burn Care Res. 31: 652-660. http://dx.doi. org/10.1097/BCR.0b013e3181e4c58c

Dinarello CA (2011). Interleukin-1 in the pathogenesis and treatment of inflammatory diseases. Blood 117: 3720-3732. http://dx.doi.org/10.1182/blood-2010-07-273417

Eniola AO, Krasik EF, Smith LA, Song G, et al. (2005). I-domain of lymphocyte function-associated antigen-1 mediates rolling of polystyrene particles on ICAM-1 under flow. Biophys. J. 89: 3577-3588. http://dx.doi.org/10.1529/ biophysj.104.057729

Fabbri LM and Rabe KF (2007). From COPD to chronic systemic inflammatory syndrome? Lancet 370: 797-799. http:// dx.doi.org/10.1016/S0140-6736(07)61383-X

Forlow SB and Ley K (2001). Selectin-independent leukocyte rolling and adhesion in mice deficient in E-, P-, and L-selectin and ICAM-1. Am. J. Physiol. Heart Circ. Physiol. 280: H634-H641.

Frey RS, Rahman A, Kefer JC, Minshall RD, et al. (2002). PKCzeta regulates TNF-alpha-induced activation of NADPH oxidase in endothelial cells. Circ. Res. 90: 1012-1019. http://dx.doi.org/10.1161/01.RES.0000017631.28815.8E

Gahmberg CG, Tolvanen M and Kotovuori P (1997). Leukocyte adhesion--structure and function of human leukocyte beta2-integrins and their cellular ligands. Eur. J. Biochem. 245: 215-232. http://dx.doi.org/10.1111/j.14321033.1997.00215.x

Ichikawa T, Nakao K, Nakata K, Yamashita M, et al. (2002). Involvement of IL-1beta and IL-10 in IFN-alpha-mediated antiviral gene induction in human hepatoma cells. Biochem. Biophys. Res. Commun. 294: 414-422. http://dx.doi. org/10.1016/S0006-291X(02)00502-8

Kanneganti TD (2010). Central roles of NLRs and inflammasomes in viral infection. Nat. Rev. Immunol. 10: 688-698. http://dx.doi.org/10.1038/nri2851

Lopez AD, Mathers CD, Ezzati M, Jamison DT, et al. (2006a). Global and regional burden of disease and risk factors, 2001: systematic analysis of population health data. Lancet 367: 1747-1757. http://dx.doi.org/10.1016/S01406736(06)68770-9

Lopez AD, Shibuya K, Rao C, Mathers CD, et al. (2006b). Chronic obstructive pulmonary disease: current burden and future projections. Eur. Respir. J. 27: 397-412. http://dx.doi.org/10.1183/09031936.06.00025805

Lozano R, Naghavi M, Foreman K, Lim S, et al. (2012). Global and regional mortality from 235 causes of death for 20 age groups in 1990 and 2010: a systematic analysis for the Global Burden of Disease Study 2010. Lancet 380: 2095-2128. http://dx.doi.org/10.1016/S0140-6736(12)61728-0

Maltais F, Decramer M, Casaburi R, Barreiro E, et al.; ATS/ERS Ad Hoc Committee on Limb Muscle Dysfunction in COPD (2014). An official American Thoracic Society/European Respiratory Society statement: update on limb muscle dysfunction in chronic obstructive pulmonary disease. Am. J. Respir. Crit. Care Med. 189: e15-e62. http:// dx.doi.org/10.1164/rccm.201402-0373ST

Menezes AM, Perez-Padilla R, Jardim JR, Muiño A, et al.; PLATINO Team (2005). Chronic obstructive pulmonary disease in five Latin American cities (the PLATINO study): a prevalence study. Lancet 366: 1875-1881. http://dx.doi. org $/ 10.1016 / \mathrm{S} 0140-6736(05) 67632-5$

Muller WA (2011). Mechanisms of leukocyte transendothelial migration. Annu. Rev. Pathol. 6: 323-344. http://dx.doi. org/10.1146/annurev-pathol-011110-130224

Genetics and Molecular Research 15 (3): gmr.15037971 
ICAM-1 and IL-1 $\beta$ promote lung injury

Rabe KF, Hurd S, Anzueto A, Barnes PJ, et al.; Global Initiative for Chronic Obstructive Lung Disease (2007). Global strategy for the diagnosis, management, and prevention of chronic obstructive pulmonary disease: GOLD executive summary. Am. J. Respir. Crit. Care Med. 176: 532-555. http://dx.doi.org/10.1164/rccm.200703-456SO

Rahman A and Fazal F (2009). Hug tightly and say goodbye: role of endothelial ICAM-1 in leukocyte transmigration. Antioxid. Redox Signal. 11: 823-839. http://dx.doi.org/10.1089/ars.2008.2204

Rahman A, Anwar KN and Malik AB (2000). Protein kinase C-zeta mediates TNF-alpha-induced ICAM-1 gene transcription in endothelial cells. Am. J. Physiol. Cell Physiol. 279: C906-C914.

Ridker PM, Thuren T, Zalewski A and Libby P (2011). Interleukin-1 $\beta$ inhibition and the prevention of recurrent cardiovascular events: rationale and design of the Canakinumab Anti-inflammatory Thrombosis Outcomes Study (CANTOS). Am. Heart J. 162: 597-605. http://dx.doi.org/10.1016/j.ahj.2011.06.012

Roebuck KA and Finnegan A (1999). Regulation of intercellular adhesion molecule-1 (CD54) gene expression. J. Leukoc. Biol. 66: 876-888.

Sin DD and Man SF (2003). Why are patients with chronic obstructive pulmonary disease at increased risk of cardiovascular diseases? The potential role of systemic inflammation in chronic obstructive pulmonary disease. Circulation 107: 1514-1519. http://dx.doi.org/10.1161/01.CIR.0000056767.69054.B3

Sin DD, Stafinski T, Ng YC, Bell NR, et al. (2002). The impact of chronic obstructive pulmonary disease on work loss in the United States. Am. J. Respir. Crit. Care Med. 165: 704-707. http://dx.doi.org/10.1164/ajrccm.165.5.2104055

Sun D, Liu ZS, Yao H, Kang SX, et al. (2011). Effects of TNF- $\alpha$ on ICAM-1 and LFA-1 expression in peripheral blood mononuclear cells of children with febrile seizures. Zhongguo Dang Dai Er Ke Za Zhi 13: 285-287.

Vogel SM, Orrington-Myers J, Broman M and Malik AB (2006). De novo ICAM-1 synthesis in the mouse lung: model of assessment of protein expression in lungs. Am. J. Physiol. Lung Cell. Mol. Physiol. 291: L496-L501. http://dx.doi. org/10.1152/ajplung.00353.2005

Zhang L, Li JT, Liu YQ, Li J, et al. (2010). Study on pathologic features of rat model of COPD. Sichuan Dong Wu 29: 285-287.

Zheng HA (2003). Research progress in establishment method of animal model of COPD. Acta Lab.Anim.Sc.Sin 11: 249252.

Genetics and Molecular Research 15 (3): gmr.15037971 